\title{
Laryngoscope-assisted and cotton ball wiping methods in prevention of oral and pulmonary infection in patients receiving mechanical ventilation and the influence on hypersensitive $\mathrm{C}$-reactive protein and procalcitonin
}

\author{
PINGJI ZHANG, GUOGUANG XIA, LI DAI, YANG CHENG and ZHUO WANG \\ Department of Respiratory Disease, Beijing Jishuitan Hospital, Beijing 100035, P.R. China
}

Received January 21, 2019; Accepted May 6, 2019

DOI: $10.3892 /$ etm.2019.7614

\begin{abstract}
Effects of laryngoscope-assisted and cotton ball wiping methods on the prevention of oral and pulmonary infection in patients receiving mechanical ventilation were compared to explore the influence of the two methods on high-sensitivity C-reactive protein (hs-CRP) and procalcitonin (PCT). In total, 152 patients who underwent mechanical ventilation in the ICU of Beijing Jishuitan Hospital from May 2005 to January 2018 were assigned and equally divided into two groups: 76 patients who had their oropharynxes scrubbed and rinsed by an electric toothbrush under direct vision by the use of a laryngoscope were selected as the laryngoscope group, and 76 patients who received the conventional cotton ball wiping method and the flushing method for oropharyngeal cleaning were assigned in the cotton ball group. Detection of serum hs-CRP and PCT levels in a 2-ml sample of fasting venous blood was performed on both groups of patients before hospitalization, and on the 5th and 10th day of hospitalization. The incidence rate of oral infection and ventilator-associated pneumonia, as well as the length of the cleaning time were recorded. The incidence rate of oral infection and ventilator-associated pneumonia in the laryngoscope group was statistically much lower than that in the cotton ball group $(\mathrm{P}<0.05)$. Before the experiment, there was no significant difference in the hs-CRP and PCT levels between the two groups $(\mathrm{P}>0.050)$, whereas the laryngoscope group had significantly lower hs-CRP and PCT levels at the 5th and 10th day of hospitalization than those in the cotton ball group $(\mathrm{P}<0.05)$. The hs-CRP and PCT levels at the three time-points in the same group were statistically different $(\mathrm{P}<0.05)$. In conclusion, oropharyngeal scrub and rinse by an
\end{abstract}

Correspondence to: Dr Guoguang Xia, Department of Respiratory Disease, Beijing Jishuitan Hospital, 31 Xinjiekou East Street, Changping, Beijing 100035, P.R. China

E-mail:v472dv@163.com; doctorwowo@aliyun.com

Key words: laryngoscope, cotton ball wiping, mechanical ventilation, oropharyngeal cleaning, oral infection, pulmonary infection, high-sensitivity C-reactive protein, procalcitonin electric toothbrush assisted by a laryngoscope, can not only better prevent oral infection and reduce the incidence of ventilator-associated pneumonia, but it also has shorter cleaning time and results in lower levels of inflammatory factors, which make this method beneficial in the clinic.

\section{Introduction}

Ventilator-associated pneumonia (VAP), a common complication of mechanical ventilation, which is receiving increasingly wider application in resolving respiratory failure, has a very high primary incidence rate of $9-60 \%$, with a daily increase of $1-3 \%$ as the mechanical ventilation continues, and a mortality rate of $26-71 \%$ (1-3). Long-term mechanical ventilation is responsible for a large number of complications, such as depression and decreased ability to live $(4,5)$. The impaired defense mechanism of patients receiving mechanical ventilation facilitates the bacterial reproduction in the oropharynx, causing respiration pneumonia, which can be prevented through the weakening of the bacterial colonization by teeth cleaning. Cleaning the oropharynx is conducive to the discharge of secretions (6). Findings have shown that high-quality care has a good effect on improving and preventing VAP (7). A previous study has suggested that chlorhexidine can reduce plaque and inhibit bacterial production, but not as well as the scrub care (8). At present, medical staff also attaches great importance to the patient's oropharyngeal care, and actively seek safe and effective care methods.

High-sensitivity C-reactive protein (hs-CRP), the most common response indicator in clinical practice, its expression is very low in blood under normal physical conditions and sharply increased during infection (9), and is widely used in the clinical evaluation of disease progression and diagnosis of disease (10). Procalcitonin (PCT), a novel infection index with low concentration in normal plasma and good stability in vivo, is related to the severity and type of the infection (11). Related literature (12) has confirmed CRP and PCT as the most sensitive indicators of inflammation in the clinic. In order to find a safe and effective oropharyngeal cleaning method that can ensure a high-quality oropharyngeal care and lower incidence of pulmonary infection, this study compared the efficacy and incidence rate of pulmonary infection of two different 
Table I. General information of the two groups [n (\%)].

\begin{tabular}{|c|c|c|c|c|}
\hline Variables & $\begin{array}{l}\text { Laryngoscope } \\
\text { group }(\mathrm{n}=76)\end{array}$ & $\begin{array}{c}\text { Cotton ball } \\
\text { group }(n=76)\end{array}$ & $\chi^{2}$ value & P-value \\
\hline Sex & & & 0.105 & 0.745 \\
\hline Male & $40(52.63)$ & $38(50.00)$ & & \\
\hline Female & $36(47.37)$ & $38(50.00)$ & & \\
\hline Age (years) & & & 0.242 & 0.623 \\
\hline$<40$ & $31(40.79)$ & $34(44.74)$ & & \\
\hline$\geq 40$ & $45(59.21)$ & $42(55.26)$ & & \\
\hline Weight $(\mathrm{kg})$ & & & 0.452 & 0.501 \\
\hline$<50$ & $26(34.21)$ & $30(39.47)$ & & \\
\hline$\geq 50$ & $50(65.79)$ & $46(60.53)$ & & \\
\hline Height $(\mathrm{cm})$ & & & 0.582 & 0.445 \\
\hline$<160$ & $16(21.05)$ & $20(26.32)$ & & \\
\hline$\geq 160$ & $60(78.95)$ & $56(73.68)$ & & \\
\hline Reason for entering ICU & & & 0.237 & 0.626 \\
\hline Medical disease & $41(53.95)$ & $38(50.00)$ & & \\
\hline Surgical disease & $35(46.05)$ & $38(50.00)$ & & \\
\hline ICU diagnose & & & 0.046 & 0.830 \\
\hline Severe pneumonia & $21(27.63)$ & $19(25.00)$ & & \\
\hline Decompensated heart failure & $18(23.68)$ & $22(28.95)$ & & \\
\hline Neurological disease & $16(21.05)$ & $17(22.37)$ & & \\
\hline Others & $21(27.63)$ & $18(23.68)$ & & \\
\hline
\end{tabular}

oropharyngeal cleaning methods given to patients in ICU ward undergoing mechanical ventilation during May 2005 to January 2018 in Beijing Jishuitan Hospital (Beijing, China), and explored the influences of the two cleaning methods on hs-CRP and PCT.

\section{Materials and methods}

General information of the two groups. One hundred and fifty-two patients on mechanical ventilation in the ICU ward from May 2005 to January 2018 in Beijing Jishuitan Hospital were selected, including 78 males and 74 females, aged $46.76 \pm 9.67$ years. According to the bed number, patients were randomized into the Laryngoscope group (76 patients) and the Cotton ball group (76 patients). The two groups of patients were comparable as no statistical difference existed as to factors including sex, age, weight, height, reason for entering ICU, and ICU diagnosis ( $\mathrm{P}>0.05$ ) (Table I).

This study was carried out with approval from the Ethics Committee of Beijing Jishuitan Hospital. Patients who participated in this research had complete clinical data. Signed informed consents were obtained from the patients or their guardians.

Two cleaning methods. Laryngoscope group: brushing with chlorhexidine solution and electric toothbrush under the direct vision of an anesthesia laryngoscope. Cotton ball group: wiping and rinsing with chlorhexidine-soaked cotton balls.

The cleaning of the two groups was performed by professional staff at the same frequency. The study was started
$4 \mathrm{~h}$ after mechanical ventilation. The oral odor before the care, the oral abnormality after the care, and the time taken were all recorded. The care lasted for the first seven days of intubation.

hs-CRP, PCT detection method. Fasting venous blood $(2 \mathrm{ml})$ was taken from each patient at 8:00 am to 10:00 am on the following day of oropharyngeal care. PCT (Shanghai Yubo Biotechnology Co., Ltd.; item no. IC-PCT-Mu) was detected using electrochemical luminescence method, hs-CRP (Shanghai Jingkang Bioengineering Co., Ltd.; item no. JK-EA00186) was detected by Turbidimetric inhibition immunoassay.

Inclusion and exclusion criteria. Inclusion criteria were: Patients without oral diseases; patients taking no immunosuppressive agents or antibiotics before oral intubation; patients with mechanical ventilation for less than $24 \mathrm{~h}$. Exclusion criteria were: Patients suffering from oral diseases; patients with hormonal drugs or receiving chemotherapy; patients with respiratory tract infection before oral intubation.

Observation indicators. Stomatitis and oral ulcers, incidence of VAP and cleaning time in the two groups were recorded. The serum levels of hs-CRP and PCT in the fasting blood samples of patients before hospitalization, the 5th day of hospitalization, and the 10th day of hospitalization were detected.

Statistical methods. The experimental data were statistically analyzed by the SPSS20.0 software package 
Table II. Comparison of stomatitis and oral ulcers between the two groups [n (\%)].

\begin{tabular}{lccc}
\hline Groups & Stomatitis & Oral ulcers & Incidence rate \\
\hline Laryngoscope group $(\mathrm{n}=76)$ & $5(6.58)$ & $3(3.95)$ & $8(10.53)$ \\
Cotton ball group $(\mathrm{n}=76)$ & $13(17.11)$ & $12(15.79)$ & $25(32.89)$ \\
$\chi^{2}$ value & 4.033 & 5.991 & 11.19 \\
P-value & 0.045 & 0.014 & 0.001 \\
\hline
\end{tabular}

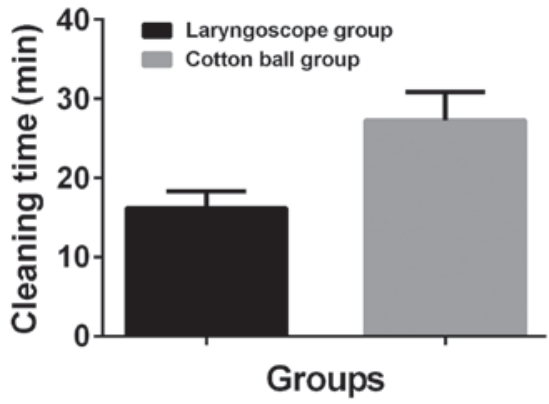

Figure 1. Comparison of the cleaning time between the two groups. The cleaning time for the 76 patients in the laryngoscope group was $16.2 \pm 2.1 \mathrm{~min}$, greatly shorter compared to the cleaning time of $27.3 \pm 3.6 \mathrm{~min}$ in the cotton ball group. The difference was statistically significant $(t=23.22, \mathrm{P}<0.001)$.

[Bizinsight (Beijing) Information Technology Co., Ltd.], and the experimental graphics were drawn using GraphPad Prism 7 software. The measurement data were expressed as mean \pm standard deviation, and the t-test was used for analysis between the two groups. The countable data were analyzed by the Chi-square test. $\mathrm{P}<0.05$ was considered to indicate a statistically significant difference.

\section{Results}

Comparison of stomatitis and oral ulcers between the two groups. Five cases of stomatitis and 3 cases of oral ulcers were recorded in Laryngoscope group, statistically less than the Cotton ball group which had 13 cases of stomatitis and 12 cases of oral ulcer $\left(\chi^{2}=4.033 \mathrm{P}=0.045, \chi^{2}=5.991 \mathrm{P}=0.014\right)$ (Table II).

Incidence of VAP in the two groups. Twelve cases of VAP were detected in the Laryngoscope group, equivalent to an incidence rate of $15.79 \%$, while the Cotton ball group had 26 cases of VAP with an incidence rate of $34.21 \%$. The incidence of VAP in the Laryngoscope group was statistically much lower than that of the Cotton ball group, and the difference was statistically significant $\left(\chi^{2}=6.877, \mathrm{P}=0.009\right)$ (data not shown).

Comparison of the time required for cleaning in the two groups of patients. The cleaning for 76 patients took the Laryngoscope group $16.2 \pm 2.1 \mathrm{~min}$, much shorter compared with the cleaning time of $27.3 \pm 3.6 \mathrm{~min}$ in the Cotton ball group, and the difference was statistically significant $(\mathrm{t}=23.22$, $\mathrm{P}<0.001$ ) (Fig. 1).

Levels of hs-CRP in the two groups before hospitalization, on the 5th day and on the 10th day of hospitalization. According to the detection, the levels of hs-CRP in the Cotton ball group before hospitalization, on the 5th day and on the 10th day of hospitalization were $1.32 \pm 0.35,0.83 \pm 0.27,0.56 \pm 0.29 \mu \mathrm{g} / 1$, respectively; the levels of hs-CRP in the Laryngoscope group before hospitalization, on the 5th day and on the 10th day of hospitalization were $1.29 \pm 0.34,0.67 \pm 0.23,0.28 \pm 0.17 \mu \mathrm{g} / 1$, respectively. The hs-CRP levels in the two groups before hospitalization were not statistically different $(\mathrm{t}=0.536$, $\mathrm{P}=0.593$ ), but the hs-CRP levels on the 5 th and 10th days of hospitalization in the Laryngoscope group were statistically lower than those in the Cotton ball group $(\mathrm{t}=3.933 \mathrm{P}=0.001$, $\mathrm{t}=7.261 \mathrm{P}<0.001)$. Compared with the hs-CRP level before hospitalization, the hs-CRP levels in the Laryngoscope group on the 5th and 10th days of hospitalization were statistically lower $(\mathrm{t}=13.53 \mathrm{P}<0.001, \mathrm{t}=23.30, \mathrm{P}<0.001)$, and the hs-CRP level on the 5th day of hospitalization was statistically much higher than that on the 10th day $(\mathrm{t}=11.89, \mathrm{P}<0.001)$. Compared with the hs-CRP level before hospitalization, the hs-CRP levels in the Cotton ball group on the 5th and 10th days of hospitalization were greatly lower $(\mathrm{t}=9.24 \mathrm{P}<0.001, \mathrm{t}=14.24$ $\mathrm{P}<0.001$ ), with a higher level on the 5th day than on the 10th day $(\mathrm{t}=5.94, \mathrm{P}<0.001)$, and the differences were statistically significant (Table III).

Levels of PCT ( $\mathrm{mg} / \mathrm{l})$ before hospitalization, on the 5th day and on the 10th day of hospitalization in both groups. According to the detection, the levels of PCT in the Cotton ball group before hospitalization, on the 5th day and on the 10th day of hospitalization were $8.65 \pm 1.76,6.51 \pm 1.06,4.91 \pm 1.12 \mathrm{mg} / 1$, respectively; the levels of PCT in the Laryngoscope group before hospitalization, on the 5th day and on the 10th day of hospitalization were $8.63 \pm 1.73,4.93 \pm 1.12$, and $2.39 \pm 1.20 \mathrm{mg} / 1$, respectively. The PCT levels in the two groups before hospitalization were not statistically different $(\mathrm{t}=0.070, \mathrm{P}=0.944)$, but the PCT levels on the 5th and 10th days of hospitalization in the Laryngoscope group were statistically lower than those in the Cotton ball group ( $\mathrm{t}=8.93 \mathrm{P}<0.001, \mathrm{t}=13.38 \mathrm{P}<0.001)$. Compared with the PCT level before hospitalization, the PCT levels in the Laryngoscope group on the 5th and 10th days of hospitalization were statistically lower $(\mathrm{t}=9.08 \mathrm{P}<0.001$, $\mathrm{t}=15.63 \mathrm{P}<0.001$ ), and the PCT level on the 5th day of hospitalization was statistically much higher than that on the 10th day $(\mathrm{t}=9.05, \mathrm{P}<0.001)$. Compared with the PCT level before hospitalization, the PCT levels in the Cotton ball group on the 5th and 10th days of hospitalization were greatly lower $(\mathrm{t}=15.65$ $\mathrm{P}<0.001, \mathrm{t}=25.84 \mathrm{P}<0.001)$, with a higher level on the 5th day than on the 10th day $(\mathrm{t}=13.49, \mathrm{P}<0.001)$, and the differences were statistically significant (Table IV). 
Table III. Levels of hs-CRP in the two groups of patients before hospitalization, and on the 5th and 10th day of hospitalization $($ mean $\pm \mathrm{SD})$.

\begin{tabular}{lccc}
\hline Groups & $\begin{array}{c}\text { Before } \\
\text { hospitalization }\end{array}$ & $\begin{array}{c}\text { 5th day of } \\
\text { hospitalization }\end{array}$ & $\begin{array}{c}\text { 10th day of } \\
\text { hospitalization }\end{array}$ \\
\hline Laryngoscope group $(\mathrm{n}=76)$ & $1.32 \pm 0.35$ & $0.67 \pm 0.23^{\mathrm{a}}$ & $0.28 \pm 0.17^{\mathrm{a}, \mathrm{b}}$ \\
Cotton ball group $(\mathrm{n}=76)$ & $1.29 \pm 0.34$ & $0.83 \pm 0.27^{\mathrm{a}}$ & $0.56 \pm 0.29^{\mathrm{a}, \mathrm{b}}$ \\
t value & 0.536 & 3.933 & 7.261 \\
P-value & 0.593 & 0.001 & $<0.001$ \\
\hline
\end{tabular}

${ }^{\mathrm{a}} \mathrm{P}<0.05$, compared to the level before hospitalization; ${ }^{\mathrm{b}} \mathrm{P}<0.05$, compared to the level on the 5 th day of hospitalization. hs-CRP, high-sensitivity C-reactive protein.

Table IV. Levels of PCT (mg/l) in the two groups of patients before hospitalization, and on the 5th and 10th day of hospitalization $($ mean $\pm \mathrm{SD})$.

\begin{tabular}{lccc}
\hline Groups & $\begin{array}{c}\text { Before } \\
\text { hospitalization }\end{array}$ & $\begin{array}{c}\text { 5th day of } \\
\text { hospitalization }\end{array}$ & $\begin{array}{c}\text { 10th day of } \\
\text { hospitalization }\end{array}$ \\
\hline Laryngoscope group $(\mathrm{n}=76)$ & $8.63 \pm 1.73$ & $4.93 \pm 1.12^{\mathrm{a}}$ & $2.39 \pm 1.20^{\mathrm{a}, \mathrm{b}}$ \\
Cotton ball group $(\mathrm{n}=76)$ & $8.65 \pm 1.76$ & $6.51 \pm 1.06^{\mathrm{a}}$ & $4.91 \pm 1.12^{\mathrm{a}, \mathrm{b}}$ \\
t value & 0.070 & 8.932 & 13.38 \\
P-value & 0.944 & $<0.001$ & $<0.001$ \\
\hline
\end{tabular}

${ }^{\text {a }}<<0.05$, compared to the level before hospitalization; ${ }^{\text {b }}<<0.05$, compared to the level on the 5th day of hospitalization. $\mathrm{PCT}$, procalcitonin.

\section{Discussion}

Patients on mechanical ventilation in ICU are at high risk of mortality (13). A required tracheal intubation for mechanical ventilation treatment as early as possible can save time for ventilation improvement to reduce morbidity and mortality $(14,15)$. Authors of a previous study concluded that the most common pathogens in ventilation and respiratory infections include Klebsiella pneumoniae, Escherichia coli and Staphylococcus (16). These are the main risk factors of VAP (17). The proliferation of oropharynx bacteria stimulated by the application of antibiotics is the primary cause of VAP, followed by the inhalation of secretions into the respiratory tract (18). Some studies have stated that simple oral cleaning is useless for the removal of plaque (19). Studies have identified the important role of a clean oral cavity in patients undergoing oral tracheal intubation in preventing VAP (20). At present, patients on mechanical ventilation are treated with the routine cleaning method, which cannot effectively eliminate oral bacteria (21). In recent years, the capability of hs-CRP and PCT has been found to be an indicator for detecting bacterial infections $(22,23)$. In order to better evaluate the effects of different cleaning methods for the prevention of VAP, patients on mechanical ventilation in Beijing Jishuitan Hospital were divided into two groups and separately received the laryngoscope-assisted cleaning method and the cotton ball wiping method. The incidences of oral odor, oral infection and VAP of the two cleaning methods and their effects on hs-CRP and PCT were compared between the two groups.

The Laryngoscope group had 5 cases of stomatitis and 3 cases of oral ulcers, with a total incidence rate of $10.53 \%$, which was statistically much lower than the incidence rate of $32.89 \%$ in the Cotton ball group that had 13 cases of stomatitis and 12 cases of oral ulcers. The difference of incidence between the two groups suggested the laryngoscope-assisted cleaning can produce a lower incidence rate of stomatitis and oral ulcers. The incidence rates of VAP in the two groups of patients were analyzed and showed a statistically greatly lower incidence in the Laryngoscope group (15.79\%) than in the Cotton ball group (34.21\%), which indicated a lower incidence of VAP by the laryngoscopy-assisted cleaning method. A shorter cleaning time of the laryngoscopy-assisted cleaning method than the cotton ball wiping method was implied: the cleaning time for 76 patients in the Laryngoscope group was $16.2 \pm 2.1 \mathrm{~min}$, statistically different from the cleaning time for 76 patients in the Cotton ball group which was $27.3 \pm 3.6 \mathrm{~min}$. The experiment was concluded by the analysis of the levels of hs-CRP and PCT in the two groups before hospitalization, on the 5th day and on the 10th day of hospitalization. The results demonstrated that no significant difference existed in hs-CRP and PCT levels between the two groups before hospitalization, but the hs-CRP and PCT levels on the 5th day and 10th day of hospitalization in the Laryngoscope group were all lower than those in the Cotton ball group, and the differences were statistically significant. Studies have shown that the levels 
of hs-CRP, PCT can be reduced by anti-infective drugs for lung infection (24).

Salehifar et al (25) identified the diagnostic value of PCT on diseases, specifically manifesting as a much higher serum PCT level at the time of infection and a gradually decreased serum PCT level when the inflammation is under control. Regarding the cleaning effect, scrubbing with an electric toothbrush assisted by the laryngoscope gives a clear sight of the cleaning site, including the deep throat; while the cotton ball wiping method has a certain blind spot where the accumulation of uncleaned secretions may result in bad breath and oral infection. As for the cleaning time, scrubbing with an electric toothbrush assisted by the laryngoscope saves time and labor, requiring only one person and causing no falling off of the conduit; while the cotton ball wiping method may demand an extra caregiver and demand more time and effort.

In summary, considering the lower incidence of oral infections and VAP, the shorter cleaning time, and the lower hs-CRP and PCT levels in the Laryngoscope group, the method of brushing with an electronic toothbrush under the direct view by the laryngoscope is more promising than the cotton ball wiping method, worthy of clinical promotion.

\section{Acknowledgements}

Not applicable.

\section{Funding}

No funding was received.

\section{Availability of data and materials}

The datasets used and/or analyzed during the present study are available from the corresponding author on reasonable request.

\section{Authors' contributions}

PZ conceived the study and wrote the manuscript. GX analyzed and interpreted the patient data. LD performed the experiment and designed the study. YC was responsible for the analysis and discussion of the data. ZW designed the methods. All authors read and approved the final manuscript.

\section{Ethics approval and consent to participate}

The study was approved by the Ethics Committee of Beijing Jishuitan Hospital (Beijing, China). Patients who participated in this research had complete clinical data. Signed informed consents were obtained from the patients or their guardians.

\section{Patient consent for publication}

Not applicable.

\section{Competing interests}

The authors declare that they have no competing interests.

\section{References}

1. Zeng YY and Zhang J: Inhaled corticoster oid and pulmonary infection. Zhonghua Jie He He Hu Xi Za Zhi 41: 362-364, 2018 (In Chinese).

2. Gugliandolo E, Fusco R, Ginestra G, D'amico R, Bisignano C, Mandalari G, Cuzzocrea S and Di Paola R: Involvement of TLR4 and PPAR- $\alpha$ receptors in host response and NLRP3 inflammasome activation, against pulmonary infection with pseudomonas aeruginosa. Shock 5: 221-227, 2019.

3. Keikha M: Importance of the identification of Segniliparus species from pulmonary infection. New Microbes New Infect 25: $1-2,2018$.

4. Bihari S, Prakash S, Hakendorf P, Horwood CM, Tarasenko S, Holt AW, Ratcliffe J and Bersten AD: Healthcare costs and outcomes for patients undergoing tracheostomy in an Australian tertiary level referral hospital. J Intensive Care Soc 19: 305-312, 2018.

5. Arttawejkul P and Kongpolprom N: A case of pulmonary infection caused by Mycobacterium asiaticum: Difficulties on diagnostic and therapeutic approaches. Respir Med Case Rep 24: 150-152, 2018

6. Shorr AF and O'Malley PG: Continuous subglottic suctioning for the prevention of ventilator-associated pneumonia: Potential economic implications. Chest 119: 228-235, 2001.

7. Garcia R, Jendresky L, Colbert L, Bailey A, Zaman M and Majumder M: Reducing ventilator-associated pneumonia through advanced oral-dental care: A 48-month study. Am J Crit Care 18: 523-532, 2009.

8. Roberts N and Moule P: Chlorhexidine and tooth-brushing as prevention strategies in reducing ventilator-associated pneumoniarates. Nurs Crit Care 16: 295-302, 2011.

9. McWilliam S and Riordan A: How to use C-reactive protein. Arch Dis Child Educ Pract Ed 95: 55-58, 2010.

10. Meinberg MC, Cheade Mde F, Miranda AL, Fachini MM and Lobo SM: The use of $2 \%$ chlorhexidine gel and toothbrushing for oral hygiene of patients receiving mechanical ventilation: Effects on ventilator-associated pneumonia. Rev Bras Ter Intensiva 24: 369-374, 2012 (In Portuguese).

11. Ramirez P, Garcia MA, Ferrer M, Aznar J, Valencia M, Sahuquillo JM, Menéndez R, Asenjo MA and Torres A: Sequential measurements of procalcitonin levels in diagnosing ventilator-associated pneumonia. Eur Respir J 31: 356-362, 2008.

12. Hausfater P: Biomarkers and infection in the emergency unit. Med Mal lnfect 44: 139-145, 2014.

13. Rajkumari N, Mathur P, Sharma S, Gupta B, Bhoi S and Misra MC: Procalcitonin as a predictor of sepsis and outcome in severe trauma patients: A prospective study. J Lab Physicians 5: 100-108, 2013.

14. Jiao J, Wang M, Zhang J, Shen K, Liao X and Zhou X: Procalcitonin as a diagnostic marker of ventilator-associated pneumonia in cardiac surgery patients. Exp Ther Med 9: 1051-1057, 2015.

15. Ratner V, Sosunov SA, Niatsetskaya ZV, Utkina-Sosunova IV and Ten VS: Mechanical ventilation causes pulmonary mitochondrial dysfunction and delayed alveolarization in neonatal mice. Am J Respir Cell Mol Biol 49: 943-950, 2013.

16. Khater WS, Salah-Eldeen NN, Khater MS and Saleh AN: Role of suPAR and lactic acid in diagnosing sepsis and predicting mortality in elderly patients. Eur J Microbiol Immunol (Bp) 6: 178-185, 2016.

17. Noguchi S, Yatera K, Kato T, Chojin Y, Furuta N, Akata K, Kawanami T, Yoshii C and Mukae H: Using oral health assessment to predict aspiration pneumonia in older adults. Gerodontology 35 : 110-116, 2018.

18. Rouzé A, Martin-Loeches I and Nseir S: Improved endotracheal tubes for prevention of ventilator-associated pneumonia: Better than silver and gold? Respir Care 64: 108-109, 2019.

19. Li Bassi G, Senussi T and Aguilera Xiol E: Prevention of ventilator-associated pneumonia. Curr Opin Infect Dis 30: 214-220, 2017.

20. Berry AM, Davidson PM, Masters J and Rolls K: Systematic literature review of oral hygiene practices for intensive care patients receiving mechanical ventilation. Am J Crit Care 16: 552-562, 2007.

21. Shkurupii D: Prevention of ventilator-associated pneumonia in newborns. Wiad Lek 71: 821-823, 2018. 
22. Wang J, Wu X, Tian Y, Li X, Zhao X and Zhang M: Dynamic changes and diagnostic and prognostic significance of serum PCT, hs-CRP and s-100 protein in central nervous system infection. Exp Ther Med 16: 5156-5160, 2018.

23. Yildiz B, Poyraz H, Cetin N, Kural N and Colak O: High sensitive C-reactive protein: A new marker for urinary tract infection, VUR andrenal scar. Eur Rev Med Pharmacol Sci 17: 2598-2604, 2013.

24. Polzin A, Pletz M, Erbes R, Raffenberg M, Mauch H, Wagner S, Arndt $\mathrm{G}$ and Lode $\mathrm{H}$ : Procalcitonin as a diagnostic tool in lower respiratory tract infections and tuberculosis. Eur Respir J 21: 939-943, 2003.
25. Salehifar E, Tavakolian Arjmand S, Aliyali M, Abedi S, Sharifpour A, Alipour A, Ala S, Eslami G, BozorgiF,Mahdavi MR, et al: Role of C-reactive protein and tumor necrosis factor-alpha in differentiating between ventilator-associated pneumonia and systemic inflammatory response syndrome without infectious etiology. Tanaffos 15: 205-212, 2016.

(i) $(9)$ This work is licensed under a Creative Commons Attribution-NonCommercial-NoDerivatives 4.0 International (CC BY-NC-ND 4.0) License. 